https://www.amerabra.org; https://fspu.uitm.edu.my/cebs; https://www.emasemasresources.com/ $9^{\text {th }}$ Asian Conference on Environment-Behaviour Studies Perdana Kota Bharu, Kelantan, Malaysia, 28-29 Jul 2021

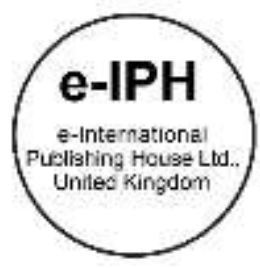

\title{
Role of Diffusion and Socio-cognitive towards Intention to use Health Portal among Health Consumers in Malaysia
}

\author{
Siti Noraini Mohd Tobi ${ }^{1}$, Erne Suzila Kassim² ${ }^{2}$ Norfazlina Ghazali ${ }^{3}$, Hendrikus Kadang ${ }^{4}$ \\ 1 Institute of Business Excellence, Universiti Teknologi MARA Shah Alam, Malaysia \\ ${ }^{23}$ Faculty of Business and Management, Universiti Teknologi MARA Selangor, Malaysia \\ ${ }^{4}$ Faculty of Economics and Business, Universitas Atma Jaya Makassar, Sulawesi Selatan, Indonesia
}

Email: snoraini7601@uitm.edu.my, ernekassim@uitm.edu.my,norfazlina4843@uitm.edu.my, hkadang71@gmail.com Tel: +60332587104

\begin{abstract}
The paper aims to examine the critical success factors that influence the attitude of health consumers and their intention to use the national health portal (MyHEALTH Portal). The study was constructed from two behavioral models; Diffusion of Innovation and Theory of Reasoned Action. It utilized an online survey hosted on the official portal website with a convenience sampling technique of 223 respondents. Results showed complexity did not significantly contribute towards attitude, while trialability and relative advantage showed significant contributions. Meanwhile, attitude influenced health consumers' intention to use the portal, while subjective norms indicated otherwise.
\end{abstract}

Keywords: Diffusion; socio-cognitive; health portal, health consumer

eISSN: 2398-4287@ 2021. The Authors. Published for AMER ABRA cE-Bs by e-International Publishing House, Ltd., UK. This is an open access article under the CC BYNCND license (http://creativecommons. org/licenses/by-nc-nd/4.0/). Peer-review under responsibility of AMER (Association of Malaysian Environment-Behaviour Researchers) , ABRA (Association of Behavioural Researchers on Asians/Africans/Arabians) and cE-Bs (Centre for Environment-Behaviour Studies), Faculty of Architecture, Planning \& Surveying, Universiti Teknologi MARA, Malaysia.

DOI: https://doi.org/10.21834/ebpj.v6i17.2809

\subsection{Introduction}

The use of the web to retrieve health information is increasingly common among health consumers. Web portal is considered an effective way to promote health education to the mass with the support of technology. In Malaysia, non-communicable diseases (e.g.cardiovascular disease, diabetes, cancer, etc.) had surpassed the communicable diseases in terms of morbidity and mortality and become the major causes of admissions and deaths in Malaysian government hospitals (Health Informatics Center Planning and Development Division, 2012). With the alarming number of national health statistics, there is still a wide gap between the community's health knowledge and behavior. Having access to any eHealth applications such as online health education services could help solve the gap. MyHEALTH Portal (MHP) is a national WBHIS set up by the Ministry of Health Malaysia in 2005. The primary function of MHP is to provide online health information for Malaysians and become a source of comprehensive, credible, accurate, and latest information on health by local health and medical experts. Though it was introduced in 2005, there is an absence of national data on scientific MHP studies where the usage outcome among health consumers is still known to be limited. This paper aims to examine the critical success factors that influence local health consumers to use the portal. Specifically, the study's objectives were to i) examine the role of diffusional factors towards health consumers' attitude and ii) examine health consumers' socio-cognitive towards portal-intention to use.

eISSN: 2398-4287@ 2021. The Authors. Published for AMER ABRA cE-Bs by e-International Publishing House, Ltd., UK. This is an open access article under the CC BYNCND license (http://creativecommons.org/licenses/by-nc-nd/4.0/). Peer-review under responsibility of AMER (Association of Malaysian Environment-Behaviour Researchers), ABRA (Association of Behavioural Researchers on Asians/Africans/Arabians) and cE-Bs (Centre for Environment-Behaviour Studies), Faculty of Architecture, Planning \& Surveying, Universiti Teknologi MARA, Malaysia.

DOI: https://doi.org/10.21834/ebpj.v6i17.2809 


\subsection{Theoretical Background}

This paper, which focuses on adopting MHP, is constructed from two behavioral models: Diffusion of Innovation Theory (DOI) and Theory of Reasoned Action (TRA). Dol is a model used to predict information system usage and has been used predominantly in technology adoption (Rogers, 1995; Rogers, 1993). TRA has been used predominantly to study human behavior, and both have been successfully used to predict intentions to adopt specific technology (Ajzen, 1991; Ajzen, 1980). As for the present paper, three Dol measures are examined; complexity, relative advantage, and trialability. Similarly, complexity has been demonstrated to be theoretically the same as Davis's perceived ease of use (Wu \& Wu, 2005; Lewis \& Orton, 2000). In contrast to Technology Acceptance Model (TAM), the present study applies complexity in Rogers' Dol theory, replacing ease of use to significantly influence portal usage. The present study also used the relative advantage to replace perceived usefulness due to the model's parsimony (Wu \& Wu, 2005; Lewis \& Orton, 2000; Jung \& Berthon, 2009). Meanwhile, the TRA's constructs investigated within the study are attitude and subjective norms.

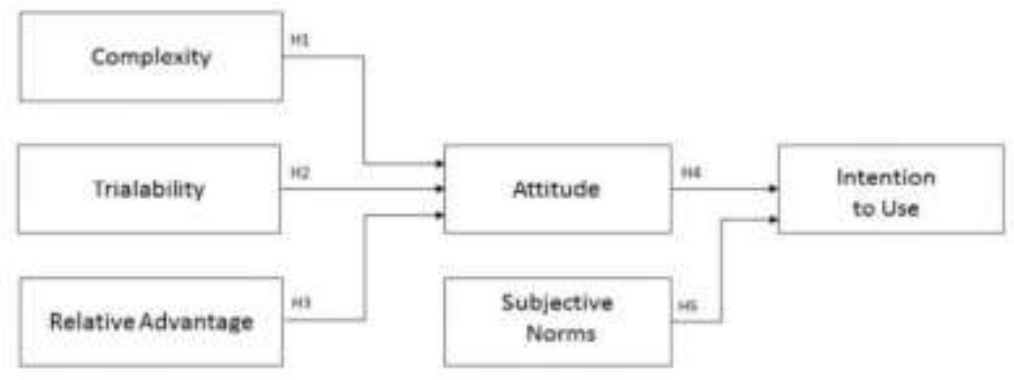

Fig. 1. Research Model

The independent variables for the study are the perceived attributes of diffusion to identify key influences on health consumers' attitude in using MHP and the socio-cognitive factors towards intention to use MHP. The research questions (RQ) and hypotheses (H) for the study are: RQ 1: What is the relationship between MHP-diffusion and health consumers' attitude in using MHP? $\mathrm{H}_{1}$ : Complexity will positively influence health consumers' attitude toward the use of MHP. $\mathrm{H}_{2}$ : Trialability will positively affect health consumers' attitude toward the use of MHP. $\mathrm{H}_{3}$ : Relative advantage will positively affect health consumers' attitude toward the use of MHP; RQ2: What is the relationship between health consumers' socio-cognitive aspect and their intention to use MHP? $\mathrm{H}_{4}$ : Attitude will positively influence health consumers' intention to use MHP. $\mathrm{H}_{5}$ : Subjective norms will positively affect health consumers' intention to use MHP.

\subsection{Methodology}

The identified population for the study is the users of MHP that access the portal at the official URL, www.myhealthportal.gov.my. The study used an online web survey hosted on the official MHP website and involved users aged between 18 to 54 years who accessed the portal during the survey conducted in November 2018. The study applied a convenience sampling technique, and the participation was based on the willingness and agreement to the terms and conditions specified in the study. Respondents gave individual consent via clicking on the consent button in the web survey before answering. The study collected 200 complete data samples, far larger than 110 , the minimum requirement for sample size in PLS-SEM estimation (Cohen, 1992; Hair et al., 2014; Hair et al., 2017). The scale for the questionnaire that was used is on a continuum from 1 to 7 . The "1" represents the level of "strongly disagree", and the "7" represents "strongly agree". The usage complexity measurement had reliability values of 0.88 (Conrad, 2009; Moore \& Benbasat, 1991). For the design complexity measurement, the scale items were adapted from the website's visual aesthetics with a reliability value of 0.71 (Moshagen \& Thielsch, 2010). The trialability items for the study were created based on the trialability concept (Rogers, 2003; Burkus, 2013; Hawkins, Mothersbaugh \& Best, 2012). The items were uniquely created to suit the trialability conditions of MHP compared to the original trialability construct (Conrad, 2009; Moore \& Benbasat, 1991). The newly constructed items are likely to explore respondents' experiences after the portal trial, while the original items tend to measure the trialability likelihoods of the product among users. The relative advantage measurement was adapted and had reliability values of 0.87 (Rogers, 2003). The user measurement attitude and subjective norms had a reliability value of 0.85 . and 0.83 (Taylor \& Todd, 1995).

\subsection{Data Analysis}

The first stage of data analysis dealt with data preparation which involved conducting a preliminary analysis to screen the data for invalid data entries. In the second stage, the main analysis was tested using Partial Least Square (PLS) path modeling using a two-stage analytical procedure; a Confirmatory Factor Analysis (CFA) to assess the measurement model followed with the structural model to confirm the proposed hypotheses.

\subsection{Preliminary Analysis}

10 out of 223 responses were incomplete due to the respondents answered the questionnaire halfway through. 13 out of 223 responses were also found invalid due to cases having suspicious response patterns (straight-lining for all questions). Meanwhile, the initial perusal 
of $z$ scores yielded 27 cases in excess of $> \pm 3.29$, indicating having univariate outliers. These 27 cases were omitted from the data set for further data analysis, and thus, only 173 cases were used in the subsequent analyses. The results from the Shapiro-Wilk test show that all variables have significant values of 0.00 and indicate the data are not normally distributed. A further test was conducted by calculating the data skewness and kurtosis values. The result of this test confirms that the data distribution is non-normal, where about $80 \%$ of the data presented skewness and kurtosis above the recommended threshold, -1 to +1 .

\subsection{Descriptive Statistics}

Table 1 highlights the demographic details of the respondents who participated in the study.

Table 1. Demographic details of respondents

\begin{tabular}{|l|l|l|l|}
\hline Characteristics & Classification & $N$ & $\begin{array}{l}\text { Percentage } \\
(\%)\end{array}$ \\
\hline \multirow{3}{*}{ Gender } & Male & 60 & 34.5 \\
\cline { 2 - 4 } & Female & 114 & 65.5 \\
\hline \multirow{5}{*}{ Age } & $18-19$ years & 3 & 1.7 \\
\cline { 2 - 4 } & $20-29$ years & 84 & 48.3 \\
\cline { 2 - 4 } & $30-39$ years & 73 & 42 \\
\cline { 2 - 4 } & $40-49$ years & 14 & 8 \\
\hline \multirow{5}{*}{ Occupational Level } & Malay & 162 & 93.1 \\
\cline { 2 - 4 } & Chinese & 11 & 6.3 \\
\cline { 2 - 4 } & Indian & 1 & 0.6 \\
\cline { 2 - 4 } & Professional & 58 & 33.3 \\
\cline { 2 - 4 } & Support & 43 & 24.1 \\
\cline { 2 - 4 } & Student & 64 & 36.8 \\
\cline { 2 - 4 } & Self-employed & 6 & 3.4 \\
\cline { 2 - 4 } & Unemployed & 4 & 2.3 \\
\hline
\end{tabular}

\subsection{Findings}

SmartPLS 3.0 statistical software application was used to analyze the measurement and structural model.

\subsection{Measurement Model Assessment}

A measurement model has satisfactory internal consistency reliability when the composite reliability of each construct exceeds the threshold value of 0.7 . The composite reliability of each construct for this study ranges from 0.926 to 0.963 , and this is above the recommended threshold value of 0.7 . A measurement model is said to have satisfactory indicator reliability when each item's loading is at least 0.7 and is significant at least at the level of 0.05 (T-value > 1.96) accounted for a 95\% confidence interval. Most items in the measurement model exhibited loadings exceeding 0.7 threshold value, suggesting that the majority of items are reliable (trialability, relative advantage, attitude, subjective norms, and intention to use). There was one construct that has an outer loading below the suggested threshold value that is from complexity $(C 5=0.616)$. $C 5$ was removed as the AVE value for complexity is increased after item removal (Hair et al., 2017). After removal, the PLS algorithm and bootstrap test were reruns, and all items finally have demonstrated satisfactory indicator reliability.

Next, the measurement model's convergent validity is assessed by examining its average variance extracted (AVE) value and considered adequate when constructs have an average variance extracted (AVE) value of at least 0.5 or more. After item deletion was made earlier due to low loadings, the new AVE value for all constructs exceeded the recommended threshold value. Next, the measurement model's discriminant validity is assessed by using three measures: 1) Fornell and Larcker's criterion, 2) cross-loading, and 3) Hetetrotrait-Monotrait Ration (HTMT). All off-diagonal elements are lower than the square roots of AVE. Hence, the result confirmed that Fornell and Larker's criterion is met.

Meanwhile, the loading of each block is higher than any other block in the same rows and columns. The cross-loadings output confirmed that the second assessments of the measurement model's discriminant validity are satisfied. Following this, all HTMT values are lower than the threshold value of 0.9 . Another assumption in HTMT that has to be fulfilled is by looking at the lower and upper bounds of the $95 \%$ confidence interval. Neither of the confidence intervals includes the value of 1 . The values of lower and upper bound for all relationships are ranging from 0.070 to 0.878 . To summarize, all model evaluation criteria have been met, providing support for the measures' reliability and validity.

\subsection{Structural Model Assessment}

All constructs-VIF values are below the threshold of 5 (VIF < 5), therefore no collinearity exists. Complexity, trialability, and relative advantage explained $67.6 \%$ of the variance in attitude.

Meanwhile, attitude and subjective norms explained $43.3 \%$ of the variance in intention to use. $R^{2}$ values range from 0 to 1 , with higher levels indicates higher levels of predictive accuracy. Following the rules of thumb, the $R^{2}$ values of attitude (0.676) can be considered substantial, whereas the $R^{2}$ value of intention to use $(0.433)$ is deemed to be moderate (Hair, Ringle \& Sarstedt, 2011).

The $f^{2}$ effect size measures the change in the $R^{2}$ value when specific exogenous (independent variables) are omitted from the model. It is used to evaluate whether the omitted predictor construct has a substantive impact on the $R^{2}$ values of the endogenous construct(s). 
The $f^{2}$ effect size of complexity and subjective norms were shown as no effect on endogenous variable $(0.018,0.012)$. Meanwhile, trialability and relative advantage's effect size towards attitude is considered as medium $(0.187,0.262)$ and attitude showed small effect size towards intention to use, respectively (0.048). To further examine the model's capability to predict, a blindfolding procedure was performed to assess the predictive relevance of the path model. The $Q^{2}$ values of both endogenous constructs are considerably above zero, which implies predictive relevance (Hair et al., 2014; Hair et al., 2017).

The $q^{2}$ effect sizes concerning all the relationships in the model revealed complexity was showing no effect on the target construct attitude $(0.010)$, while the relationship between trialability and relative advantage on attitude can be considered medium as the values are slightly near 0.15 . Meanwhile, for target construct intention to use, attitude has a small effect in producing the predictive relevance with the effect size value of 0.041 . On the other hand, subjective norms have a $q^{2}$ effect size of 0.02 on intention to use. Although the value indicates a small effect in predicting relevance, this value is on the borderline near the no-effect predictive relevance. Thus, the path coefficient result of subjective norms can confirm this relationship. The earlier path found no significant correlation between subjective norms and intention to use.

The final step confirms the significant effect of exogenous variables on endogenous variables despite the effect size and variance. The results indicate that all paths are statistically significant using a two-tailed test (t-value $>1.96)$ except for complexity $(t=1.213)$ and subjective norms ( $t$ value $=0.854$ ). Table 2 . below lists the path coefficients, observed $t$-statistics, significance level values, and the confidence intervals for all hypothesized paths.

Table 2. Results of the hypothesized path

\begin{tabular}{|c|l|c|c|c|c|}
\hline Hypotheses & Relationship & $\begin{array}{c}\text { Path } \\
\text { coefficient }\end{array}$ & t Values & P values & $\begin{array}{c}\text { Significance } \\
(p<0.001)\end{array}$ \\
\hline H1 & Complexity $\rightarrow$ Attitude & 0.113 & 1.213 & 0.226 & NS \\
\hline H2 & Trialability $\rightarrow$ Attitude & 0.364 & 4.896 & 0.000 & $* *$ \\
\hline H3 & Relative Advantage $\rightarrow$ Attitude & 0.437 & 5.696 & 0.000 & $* *$ \\
\hline H4 & Attitude $\rightarrow$ Intention to use & 0.233 & 2.559 & 0.011 & $*$ \\
\hline H5 & $\begin{array}{l}\text { Subjective norms } \rightarrow \\
\text { Intention to use }\end{array}$ & -0.092 & 1.331 & 0.184 & NS \\
\hline
\end{tabular}

The assessment of the path coefficient in Table 2. shows that more than half of the proposed hypotheses were supported that are; $\mathrm{H} 2, \mathrm{H} 3$, and $\mathrm{H} 4$. From the analysis, supported assumptions are significant at least at the level of 0.05 , have expected sign directions (i.e., positive), and consist of a path coefficient value ( $\beta$ ) range from 0.233 to 0.437 . With regards to the predictor of health consumers' attitude in using MHP, results showed complexity did not significantly influence the relationship $(\beta=0.113, t=1.213, p>0.001)$ while trialability $(\beta=0.364, t=4.896, p<0.001)$ and relative advantage $(\beta=0.437, t=5.696, p<0.001)$ showed significant influences. Meanwhile, the attitude was significantly found influenced intention to use $(\beta=0.233, t=2.559, p<0.001)$ while subjective norms were found not to show a statistically significant relationship with intention to use $(\beta=-0.092, t=1.331, p>0.001)$.

\subsection{Discussion}

As been noted earlier within the study, complexity has been demonstrated to be theoretically the same as Davis's perceived ease of use (Wu \& Wu, 2005; Lewis \& Orton, 2000). Within the discussion of this study, empirical findings relating to the relationship between complexity and attitude were highlighted based on previous WBHIS results on both constructs: complexity and ease of use towards health consumers' attitude since the absence of findings relating to complexity constructs within the study area. Overall, this study suggested that the portal's complexity level does not contribute to the health consumers' attitude towards MHP usage. This result is not consistent with previous studies that had examined complexity and ease of use towards users' attitude in using WBHIS (Lazard \& Mackert, 2014; Yun \& Park, 2010). For instance, one previous study examined the relationships of the factors affecting consumers' disease information-seeking behavior on the Internet in Korea (Yun \& Park, 2010). In that study, perceived ease of use was found to positively affect consumers' attitudes towards their use of disease information on the Internet. Within this study, the result is not something peculiar as only a small number of studies within WBHIS had found that complexity and ease of use significantly influenced health consumers' attitude towards using the health care portals (Lazard \& Mackert, 2014; Yun \& Park, 2010). This is due to some researchers had ignored this component due to its mediating role towards usage intention (Adams, Nelson \& Todd, 1992; Davis, Bagozzi \& Warshaw, 1992) cited in Wong et al. (2012).

Many researchers within the field were found emphasizing the direct impact of complexity and ease of use on the behavioral intention of technology adoption without considering the effect of attitude (Ning, Jiang \& Kim, 2014; Chang \& Im, 2014; Jung \& Loria, 2010). Besides that, the study had revealed; trialability has a positive influence on the health consumers' attitude toward MHP. Given the limitations of existing studies on relative advantage and WBHIS, previous research in website personalization had supported this finding.

For instance, one study had found that trialability significantly impacted attitudes toward website usage (Greer \& Murtaza, 2003), and another recent finding on trialability also found it significantly affecting the adoption of E-Health among health users (Manish et al., 2021). (Likewise, trialability has been conceptualized in prior research as a belief signifying opportunity to experiment with a technical innovation 
would facilitate its adoption (Banerjee, Wei \& Ma, 2012). It also has been highlighted that the lack of trialability in terms of web usage may quickly hamper growth and ward off new users (Barnett, Fink \& Debus, 1989). This study confirms that trialability is one of the determinants of the health consumers' positive attitude towards technology, specifically the MHP.

Also, empirical findings relating to the relationship between relative advantage and attitude are highlighted based on previous WBHIS results on both constructs: relative advantage and perceived usefulness towards health consumers' attitude given the limitations of existing studies relating to relative advantage's construct within the study area. This study had suggested that MHP-relative advantage positively influenced the health consumers' attitude towards MHP usage and determined as the key essential factor affecting MHP-health consumers' attitude towards the use of MHP. This result is also consistent with previous studies that had examined WBHIS-usefulness and health consumers' attitudes (Jung \& Berthon, 2009; Yun \& Park, 2010; Jung \& Loria,2010) given the absence of empirical findings investigating the area using relative advantage's construct. Another recent study also identified relative advantage as the prime stimulators for the adoption of E-Health platforms (Manish et al., 2021). For instance, a study was conducted on factors affecting consumers' disease information-seeking behavior on the Internet in Korea. In the study, perceived usefulness was found to directly and positively influenced Korean health consumers' attitude, although it was not identified as the critical factor influencing the results (Yun \& Park, 2010).

Within the study, attitude has been identified to have a positive influence on health consumer's intention to use MHP. This result is consistent with previous studies that examined users' intention towards WBHIS use (Jung \& Berthon, 2009; Yun \& Park, 2010; Jung \& Loria,2010; Wong et al., 2012; Dahlgren et al., 2012a; Dahlgren, Sørum \& Helseth, 2012b). For instance, a study was investigating the predictors of internet use to search for online health information among Chinese older adults. In that study, attitude was identified as the predictive of the behavioral intention of Internet use for health information (Wong et al., 2012). In that study, perceived ease of use-users' intentions' significant finding contributed to this result. Specifically, when older people do not encounter difficulties in using the Internet and possess positive attitudes toward Internet use, they show greater willingness to seek health information from the Internet.

Another recent study by Pichandy, Rathinaswamy and Koothoor (2020) consolidates the findings that the precipitating factor through attitude influenced the successful acceptance and use of technology.

Finally, this study had suggested health consumer's subjective norms do not contribute to their intention to use MHP. This result is consistent with previous studies that had examined subjective norms towards users' intention to use WBHIS. The study evaluated the effects of the evidence-based health information portal compared to no intervention group in a real-life setting, which the research grounded on TPB as the predicting theory (Dahlgren, et al., 2012a). The results revealed, the subjective norm was not significant as a predictor of intention in both groups. This result is aligned with another study to examined significant predictors associated with intention to search for health information which also found subjective norms as not a significant predictor towards intention (Dahlgren, Sørum \& Helseth, 2012b). Both findings support the present study showing that social expectations or pressure do not appear to be a critical or positive predictor of intention to search.

\subsection{Conclusion}

The study is focused solely on health consumers in identifying the critical factors of MHP usage intention. The results would be more interesting if outputs from the professionals' perspectives are also examined. The professionals consist of the key players in the health promotion area including healthcare consultants, physicians, health educators and the health policy makers would offer noteworthy viewpoints particularly on the limitations and practical solutions of the portal. Thus, it is strongly suggested to include the key players of the industry within the future study of WBHIS. In general, the findings would help the Ministry of Health, Malaysia identify the critical success factor of the health portal usage. Significantly, the results helped in coherently understand the indispensable role of trialability towards health consumers' attitude. The Ministry can benefit from redesigning the portal's future strategy to increase MHP usage among the society. Several spots of attraction such as hospitals and clinics' setting, schools, universities, and public seminars can help reach target users towards MHP trialability. This effort would help minimize the gaps towards MHP's utilization due to the public unaware of the portal existence.

\subsection{Paper Contribution to Related Field of Study}

The study wishes to provide few significant contributions within the field of information technology. First, it investigates a new hybrid term of complexity where it combined two perspectives of complexity's definition from Rogers-complexity (Rogers, 2003) and the design complexity (Pieter, Wedel, \& Batra, 2010). The addition of design complexity into complexity construct is the researcher's attempt to investigate the enhanced meaning of complexity, which incorporates usage complexity and design complexity, significant in portal usage among health consumers. Second, the study examined the trialability in a different spectrum compared to the original measurement. The actual items are inclined to measure on trialability likelihoods of the product among users (Conrad, 2009; Moore and Benbasat,1991), whereas newly constructed items prone to explore users' experiences after they were allowed to try out MHP. Since the study has confirmed trialability as a predictor that influences users' attitudes towards MHP usage, other studies within the field of information and technology could replicate the newly developed measurement within thisstudy.

\section{References}

Adams, D. A., Nelson, R. R., Todd, P. A. (1992). Perceived usefulness, ease of use, and usage of information technology: a replication. MIS Quarterly. 16(2), 227-247. 
Ajzen, I. (1991). The Theory of Planned Behavior. Organizational Behavior and Human Decision Process. 50, $179-211$.

Ajzen, I., and Fishbein, M. (1980). Understanding Attitudes and Predicting Social Behavior. NJ: Prentice-Hall, Inc.

Banerjee, P., Wei, K.K. and Ma, L. (2012). Role of Trialability in B2B E-Business Adoption: Theoretical Insights from Two Case Studies. Behaviour and Information Technology. 31(9), 815-827.

Barnett, G. A., Fink, E. L., and Debus, M. (1989). A Mathematical Model of Academic Citation Age. Communication Research. 16, 510-531.

Burkus, D. (2013). The Myths of Creativity: The Truth About How Innovative Companies and People Generate Great Ideas. San Francisco, CA: Jossey-Bass.

Chang, S. J. and Im, E. O. (2014). A Path Analysis of Internet Health Information Seeking Behaviors Among Older Adults. Geriatric Nursing. 35, $137-141$.

Cohen, J. (1992). A Power Primer. Psychological Bulletin. 112, 155-159.

Conrad, E. D. (2009). Willingness to Use IT Innovations: A Hybrid Approach Employing Diffusion of Innovations and Technology Acceptance Models. Doctor Philosophy, Southern Illinois University. Retrieved May, 5, 2018, from http://search.proquest.com.ezaccess.library.uitm.edu.my/docview/304996660?accountid=42518 ABI/INFORM Complete; ProQuest Dissertations \& Theses Full Text database.

Dahlgren, A. A., Bjørndal, A., Jensen, J. O. and Helseth, S. (2012a). Evaluation of a Web Portal for Improving Public Access to Evidence-Based Health Information and Health Literacy Skills: A Pragmatic Trial. Plos One. 7(5), n.p.

Dahlgren, A. A., Sørum, R., and Helseth, S. (2012b). Cognitive Factors Predicting Intentions to Search for Health Information: An Application of the Theory of Planned Behaviour. Health Information and Libraries Journal. 29(4), 296-308.

Davis, F. D., Bagozzi, R. P. and Warshaw, P. R. (1992). Extrinsic and Intrinsic Motivation to Use Computers in the Workplace. Journal of Applied Social Psychology. 22(14), 1111-1132

Greer, T., and Murtaza, M., (2003). Web personalization: The impact of perceived innovation characteristics on the intention to use personalization. Journal of Computer Information Systems. 43(3), 50-55.

Hair, J. F., Hult, G.T.M., Ringle, C.M. and Sarstedt, Marko (2014). A Primer on Partial Least Squares Structural Equation Modeling (PLS-SEM). London: Sage Publications.

Hair, J. F., Hult, G.T.M., Ringle, C.M. and Sarstedt, Marko (2017). A Primer on Partial Least Squares Structural Equation Modeling (PLS-SEM) (2nd ed.) London: Sage Publications.

Hair, J. F., Ringle, C. M., and Sarstedt, M. (2011). PLS-SEM: Indeed a Silver Bullet. Journal of Marketing Theory and Practice. $19,139-151$.

Hawkins, D. I., Mothersbaugh, D. L. and Best, R. (2012). Consumer Behavior: Building Marketing Strategy. McGraw-Hill.

Health Informatics Center Planning and Development Division Ministry of Health Malaysia (2012). Health Facts 2012. Retrieved October 8, 2018, from http://www.moh.gov.my/images/gallery/stats/heal_fact/health_fact_2012_page_by_page.pdf.

Jung, M. L. and Berthon, P. (2009). Fulfilling the Promise: A Model for Delivering Successful Online Health Care. Journal of Medical Marketing: Device, Diagnostic and Pharmaceutical Marketing. 9, 243.

Jung, M. L. and Loria, K. (2010). Acceptance of Swedish e-health Services. Journal of Multidisciplinary Healthcare. 3, 33-63.

Lazard, A. and Mackert, M. (2014). User Evaluations of Design Complexity: The Impact of Visual Perceptions for Effective Online Health Communication. International Journal of Medical Informatics. 83, 726-735.

Lewis, N. and Orton, P. (2000). The Five Attributes of Innovative e-Learning. Training and Development. 54(6), 47-51.

Manish, P., Nandhini, B., Jhoti, S., and Numrata, M., (2021). Assessing E-Health Adoption Readiness Using Diffusion Of Innovation Theory And The Role Mediated By Each Adopter's Category In A Mauritian Context, International Health, ihab035.

Moore, G. C. and Benbasat, I. (1991). Development of an Instrument to Measure the Perceptions of Adopting an Information Technology Innovation. Information Systems Research. 2(3), 192-222.

Moshagen, M. and Thielsch, M. T. (2010). Facets of visual aesthetics. International Journal of. Human-Computer Studies. 68 (10), $689-709$.

Ning, X., Jiang, Z. and Kim, K. (2014). An Empirical Study on Factors Affecting Usage Intention of Healthcare Information Service among College Students. International Journal of Engineering and Industries. 5(1), n.p.

Pichandy, C., Rathinaswamy, J., and Koothoor, P. (2020). Technology acceptance by medical doctors in India: an analysis with UTAUT model. Int J Sci Technol Re. 9:3854-7.

Pieter, R., Wedel, M. and Batra, R. (2010). The Stopping Power of Advertising: Measures and Effects of Visual Complexity. J. Mark. 74 (5), $48-60$.

Ringle, C. M., Wende, S., and Becker, J. M. (2015). SmartPLS 3.0. Boenningstedt: SmartPLS GmbH, Retrieved September, 5, 2018, from http://www.smartpls.com.

Rogers, E. (1995). Diffusions of Innovations. (4th ed.). New York: Free Press 
Rogers, E. (2003). Diffusion of Innovations. (5 $5^{\text {th }}$ ed.) New York: Simon and Schuster.

Taylor, S., and Todd, P. A. (1995). Understanding Information Technology Usage: A Test of Competing Models. Information Systems Research. 6(2), $144-176$.

Wong, C. K. M., Yeung, D. Y., Ho, H. C. Y, Tse, K. and Lam, C. Y. (2012). Chinese Older Adults' Internet Use for Health Information. Journal of Applied Gerontology. 33, 316.

Wu, L. and Wu, K. (2005). A Hybrid Technology Acceptance Approach for Exploring e-CRM Adoption in Organizations. Behaviour and Information Technology. 24(4), 303-316.

Yun, E. K. and Park, H. A. (2010). Consumers' Disease Information-Seeking Behaviour on the Internet in Korea. Journal of Clinical Nursing. 19(20), 2860-8. 